\title{
Method to determine the dosage of bituminous tack coat in function of the texture of milled asphalt layers to be overlaid
}

\author{
Recto running head : INTERNATIONAL JOURNAL OF PAVEMENT ENGINEERING \\ Verso running head : J. RIVERA ET AL. \\ Julián Rivera ${ }^{a}$, Hugo D Bianchetto ${ }^{b}$, Adriana H. Martínez ${ }^{c}$ \\ aLa Plata Regional Faculty, National Technological University, La Plata, Argentina \\ ${ }^{\text {b} A v e l l a n e d a ~ R e g i o n a l ~ F a c u l t y, ~ N a t i o n a l ~ T e c h n o l o g i c a l ~ U n i v e r s i t y, ~ A v e l l a n e d a, ~ A r g e n t i n a ~}$ \\ 'Technical University of Catalonia-BarcelonaTech, Barcelona, Spain
}

CONTACT Adriana H. Martínez adriana.martinezupc.edu Area of Transport and Regional Planning Technical University of CataloniaBarcelonaTech Jordi Girona 1-3, Módulo B-1, 08034 Barcelona, Spain

History : received : 2018-06-28 accepted : 2019-01-24

Copyright Line: (c) 2019 Informa UK Limited, trading as Taylor \& Francis Group

\section{ABSTRACT}

In the rehabilitation of flexible pavements with asphalt layers, it is necessary to apply a bituminous tack coat with a pre-established dosage, which usually does not take into account the degree of texture generated if a milling operation is previously performed since this increases the surface at the interface. On the other hand, when milling, grooves are obtained that could lead to the runoff of bitumen emulsion with excessive deposition in their valleys due to dosages greater than those needed. This work analyses the above mentioned and achieves a compromise solution, with its corresponding method of application, based on the mechanical behaviour obtained with different degrees of texture and validated for typical materials used in Argentina.

\section{KEYWORDS}

Road engineering; asphalt Overlays; pavement milling; bituminous tack coat

\section{FUNDING}

This work was supported by Argentine Ministry of Education [grant number IFI4708TC][AQ1].

\section{Introduction}

During the operation of a flexible pavement road, activities are carried out aimed at its rehabilitation, sometimes eliminating part of the wearing course by means of milling techniques, avoiding the influence of the rutting of the existing layer and eliminating the thickness increase (Miller and Bellinger 2003, NCHRP 2004, Martínez-Echevarría 2012). This task requires the use of rotating equipment, equipped with milling tools that may have different characteristics, allowing several degrees of texture, different from the original surface, which can be considered 'smooth' in relative terms (Delbono 2014, Wirtgen 2015).

Before placing the overlay, it is necessary to provide an asphalt emulsion tack coat to generate an adequate interface (Bussard 2014), so that if the existing pavement has a good structural condition, the stresses and deformations generated by the traffic effect do not affect the expected lifetime (Espinoza 2015, Montetrusque et al. 2015). Considering that milling produces a grooved surface which increases the existing pavement surface, a corresponding increase in tack coat will be necessary when compared to a non-milled surface. There are few studies that have addressed this subject. For this reason, this work was developed, within the framework of a doctoral thesis in materials engineering, carried out mainly in LEMaC, the Road Research Center of the Universidad Tecnológica Nacional, Facultad Regional La Plata, Argentina.

The objective of this study is to evaluate the effect of the increase of surface area of the milled pavement on the tack coat dosage. 


\section{State of the art}

The structural analysis of the interface will be conditioned to the structural model that will be used (Uzan et al. 1978, EICAM 1998). Specifically, in multilayer flexible pavements, traffic loads induce stresses in the structure that are absorbed by the set of different layers, from the upper layer to the lower layers of the pavement and the subgrade (Giovanon and Buono 2008, Yaacob et al. 2014); thus, an adequate modelling of the interface leads to optimising the costs of a rehabilitation (Romanoschi 1999) if the incidence of milling and its characteristics in each particular case is considered (Brown and Brunton 1984). Most researchers developed new prototypes to improve their investigations, demonstrating that shear stress tests are a good and effective method of analysis (Santagata et al. 2009, Diakhaté et al. 2011, Giovanon and Pagola 2012, Raposeiras et al. 2013). The mechanical models of interfaces express the relationship between the shear displacement along the interface plane and the normal and shear stresses. Evaluating the static stresses to failure, Romanoschi (1999) reported that the results obtained could be represented with a simplified model, which consists of two stages, the elastic response and the friction one (for each representative reference temperature), as shown in Figure 1. In the first stage, the Shear Displacement (TD) is proportional to the shear stress (Goodman's model), the proportionality being the interface reaction modulus $(K)$ in the horizontal direction, up to the Maximum Shear Strength (Smax) when failure takes place. Once the interface fails, the second stage starts and can be described as friction between layers (characterised by the friction coefficient $\mathrm{mu}$ ).

Figure 1. Simplified constituent model of the asphalt-asphalt interface (Romanoschi 1999).

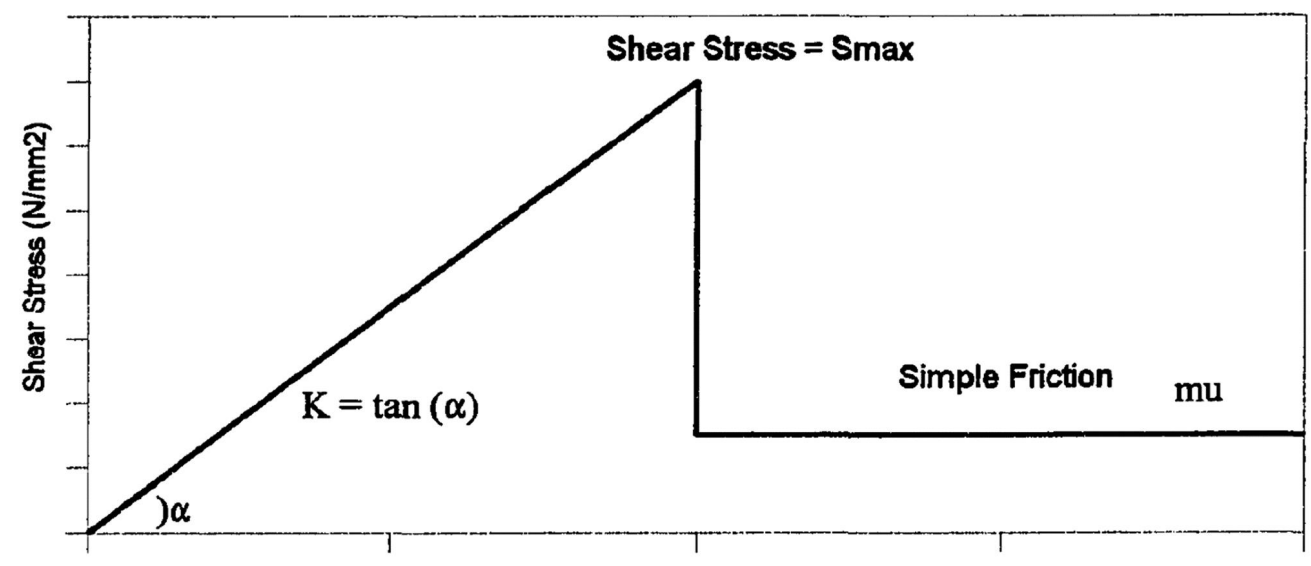

Shear Displacement (mm)

The relationship between the existing surface and the applied overlay depends mainly on the amount of residual asphalt binder in the bituminous emulsion tack coat (parameter used to specify the tack coat dosage) (Ricci 2011). The National Highway Administration of Argentina (in Spanish Dirección Nacional de Vialidad, DNV) specifies the use of a cationic rapid setting emulsion with a dosage that ensures a minimum shear resistance of $0.7 \mathrm{MPa}$ at the interface according to EN 12697-48 Standard with SBT method (DNV 2017). But there is no particular specification for pavement rehabilitation when the existing layer is subjected to a surface milling as can found in USA for example (Gierhart 2018[AQ2]). Figure 2 shows an image of the SBT device.

Figure 2. Shear bond test (SBT) (Montetrusque et al. 2015).

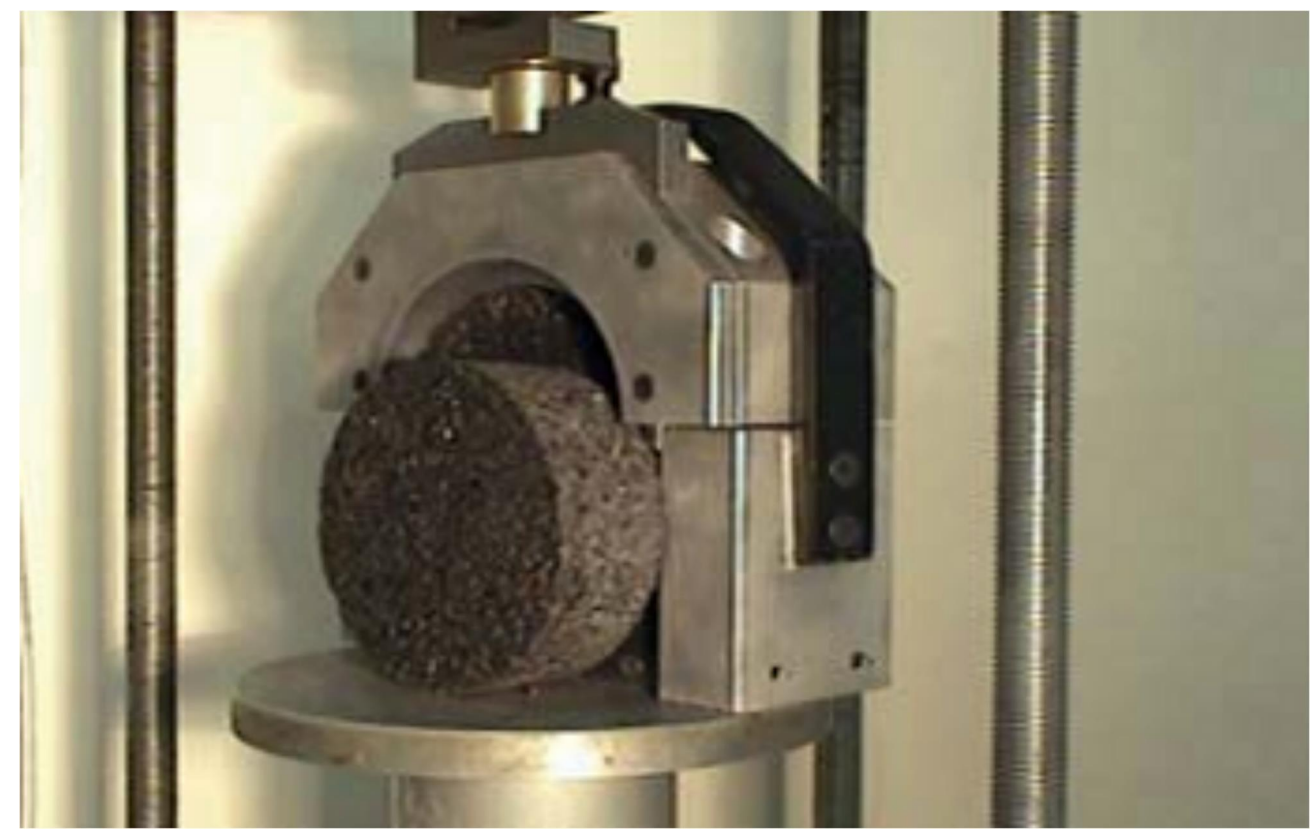




\section{Materials and methods}

The methodology consisted of the following steps:

\subsection{Determination of the optimum tack coat content for non-milled surface}

In order to evaluate the influence of the surface increase at the interface of the bilayer systems, it is necessary to define first a tack coat dosage for the case of the non-existence of milling in the interface ('smooth' surface). For this purpose, the bilayer system was studied in laboratory with a double specimen prepared with two layers of asphalt mixture and a rapid setting cationic asphalt emulsion for the tack coat application at the interface. A dense hot asphalt concrete with a maximum aggregate size of 19 mm (CAC-D19) for both the upper and lower layers of the double specimens was selected. Considering the approximate allocations recommended by the reference literature, it was decided to analyse the tack contents of $0.0 \mathrm{l} / \mathrm{m}^{2}, 0.1 \mathrm{l} / \mathrm{m}^{2}, 0.2 \mathrm{l} / \mathrm{m}^{2}, 0.3 \mathrm{l} / \mathrm{m}^{2}$ and $0.4 \mathrm{l} / \mathrm{m}^{2}$. By establishing three replicates per each content, 15 double specimens were manufactured, as can be seen in Figure 3. Density of the specimens was determined and the results presented a tendency to the normal distribution with an average value of $99.4 \%$ with respect to the Marshall reference density, which is considered a sufficiently approximate value, since it verifies the specified methodology.

Figure 3. Double samples 1-12 \& I to III.

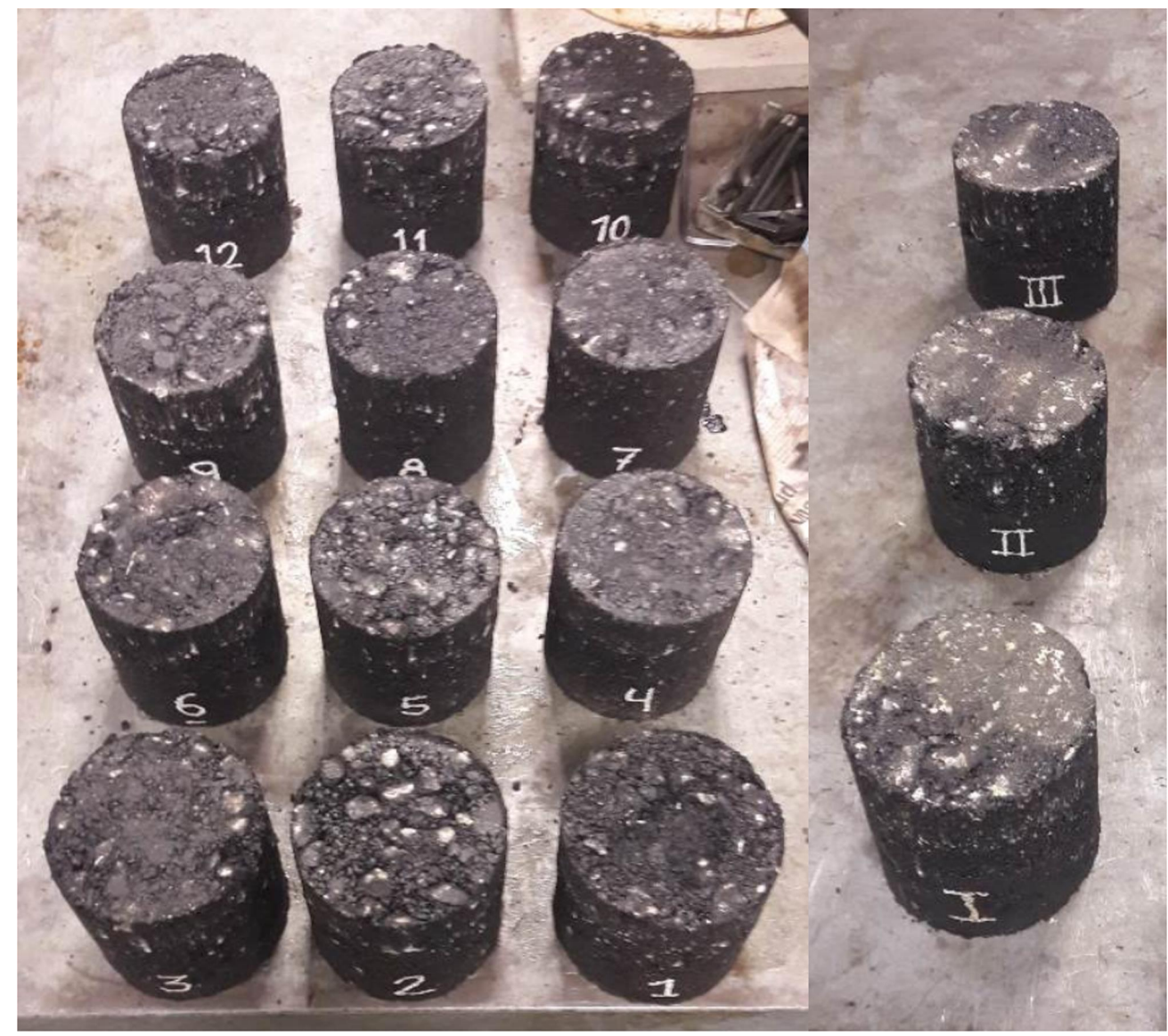

There are numerous tests worldwide, since different researchers have not yet agreed on which to use (Tosticarelli 2002, Muench and Moomaw 2008). However, pure direct shear tests represent the most common ones in the applying shear displacement and recording shear stress (Giovanon 2012). The test selected in the present work subjects the specimens to pure shear stress in a parallel direction to the interface of the tack coat, Figure 4. The theoretical model used to calculate the shear stress and displacement was the one described in Section 2 (first stage of Goodman's model) and shown in Figure 1.

Figure 4. Selected test in this research. 


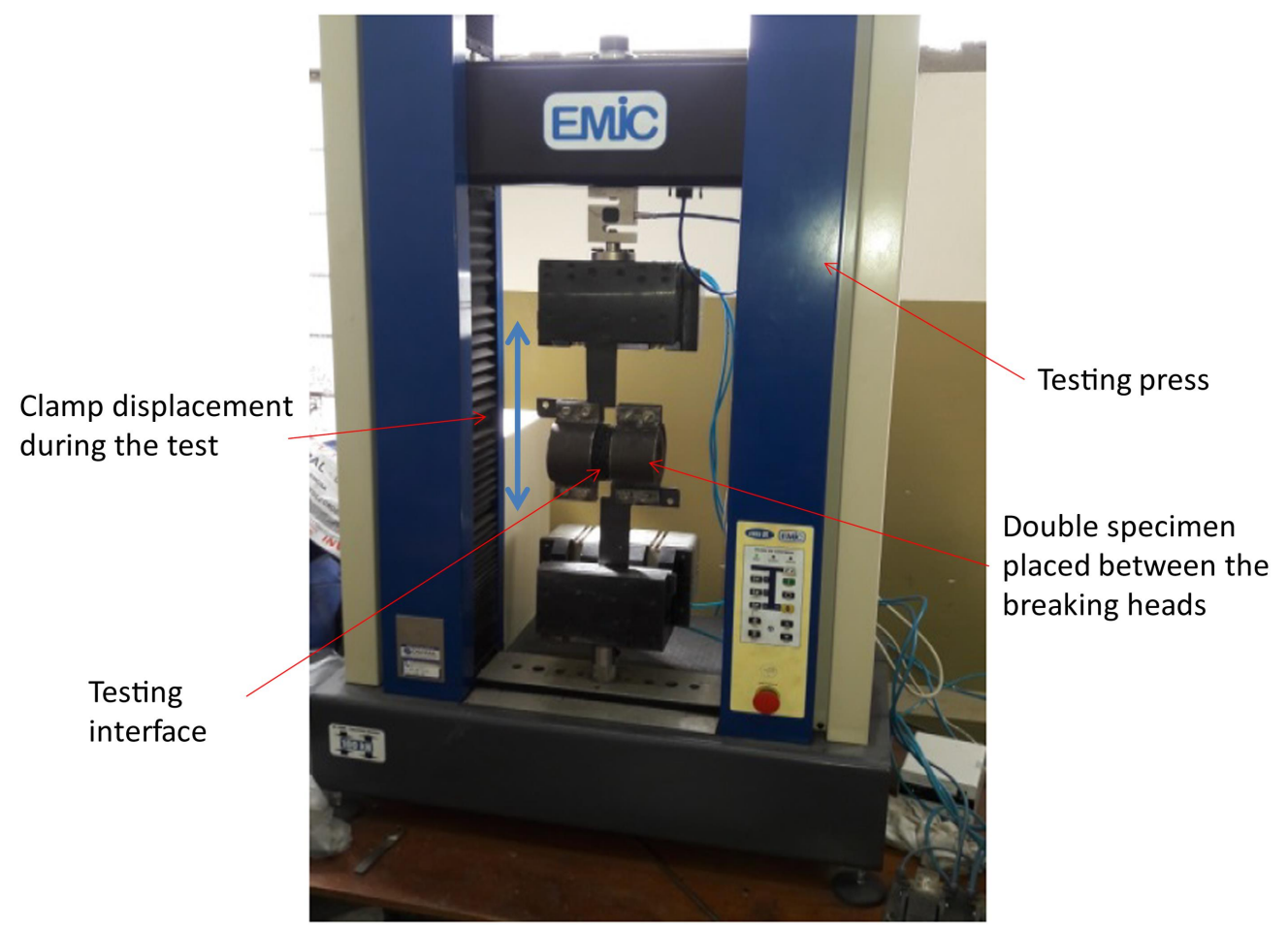

Based on the data collected and the experiences by Delbono (2014) and Ricci (2011) at the LEMaC facilities, it was decided to generate the shear stress in the plane to be evaluated at a controlled piston speed of $1.27 \mathrm{~mm} / \mathrm{min}$ and establish the test temperature at $20^{\circ} \mathrm{C}$.

The research team led by D'Andrea (2013) revealed that double cylindrical specimens prepared with the Marshall compactor can be made by applying the compaction only on one surface. Ricci (2011) carried out studies of series of double specimens made with an analogous methodology of compaction, determining that the difference of densities along the height of the specimen are statistically negligible. To carry out this test, the bituminous tack coat is applied between both layers with a standardised curing process in the laboratory, using a forced ventilation oven at temperatures close to $60^{\circ} \mathrm{C}$ (Yaacob et al. 2014). These double specimens are moulded with a thickness of 50 $\mathrm{mm}$ for both the base layer and the overlay. The clamps that surround the upper and lower part of the double specimen were separated by about $30 \mathrm{~mm}$ to allow the development of the milled interface, generating in addition to the own deformation that takes place at the interface another deformation close to the interface related to the specimen in this area, as can be seen in Figure 5 . Therefore, the tangential deformations and the shear stresses are different from those obtained with the SBT, where the clamps are separated by a minimum distance. For this reason, the results of TD and Smax to be obtained in this work are only comparatively relative to each other and not to those generated by other test methodologies.

Figure 5. Deformation in the central area of the double specimen during the test.
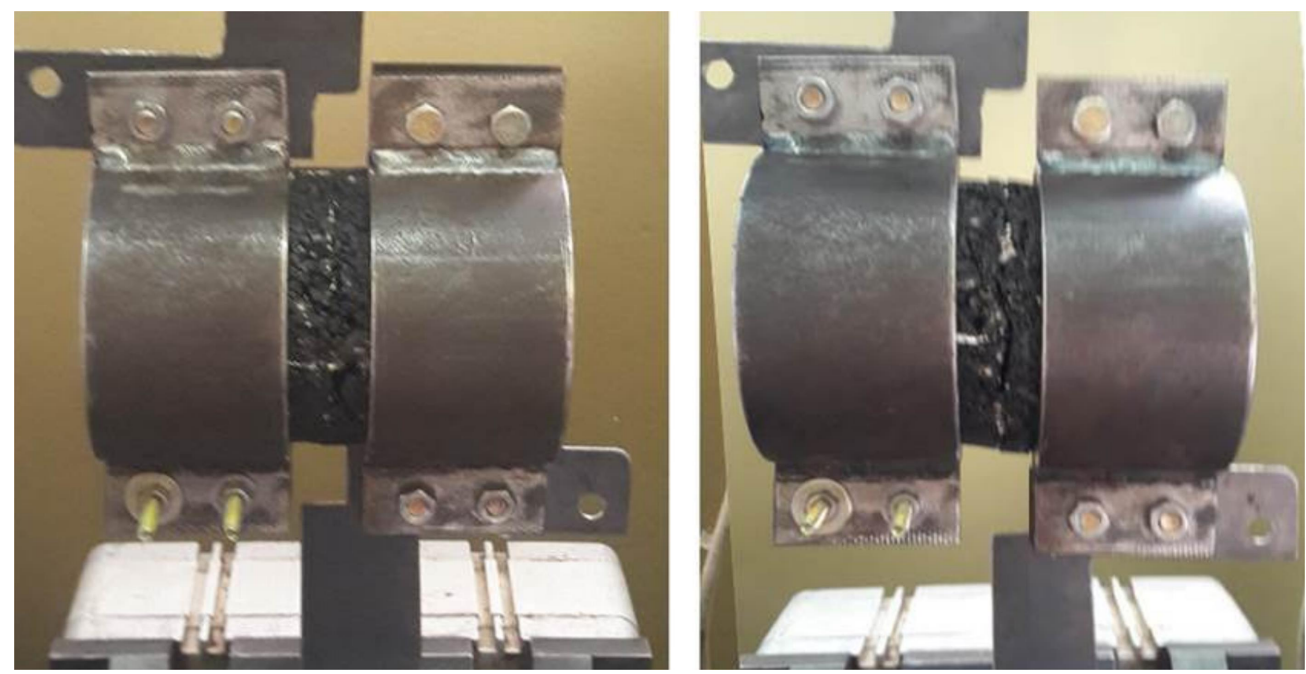

Differences among the results obtained for the dosages studied could be identified with the equipment used, since the load cell was able to measure up to $20000 \mathrm{~N}$ with and accuracy of $1 \mathrm{~N}$. Figure 6 shows a set of resulting type curves and the analysis parameters obtained for the series of samples tested, corresponding to the $0.1 \mathrm{l} / \mathrm{m}^{2}$ dosage. In this figure, the curves for each sample have been displaced on the displacement axis a distance corresponding to $4.0 \mathrm{~mm}$, to allow a better observation.

Figure 6. Results for the test samples with content $0.1 \mathrm{l} / \mathrm{m}^{2}$. 


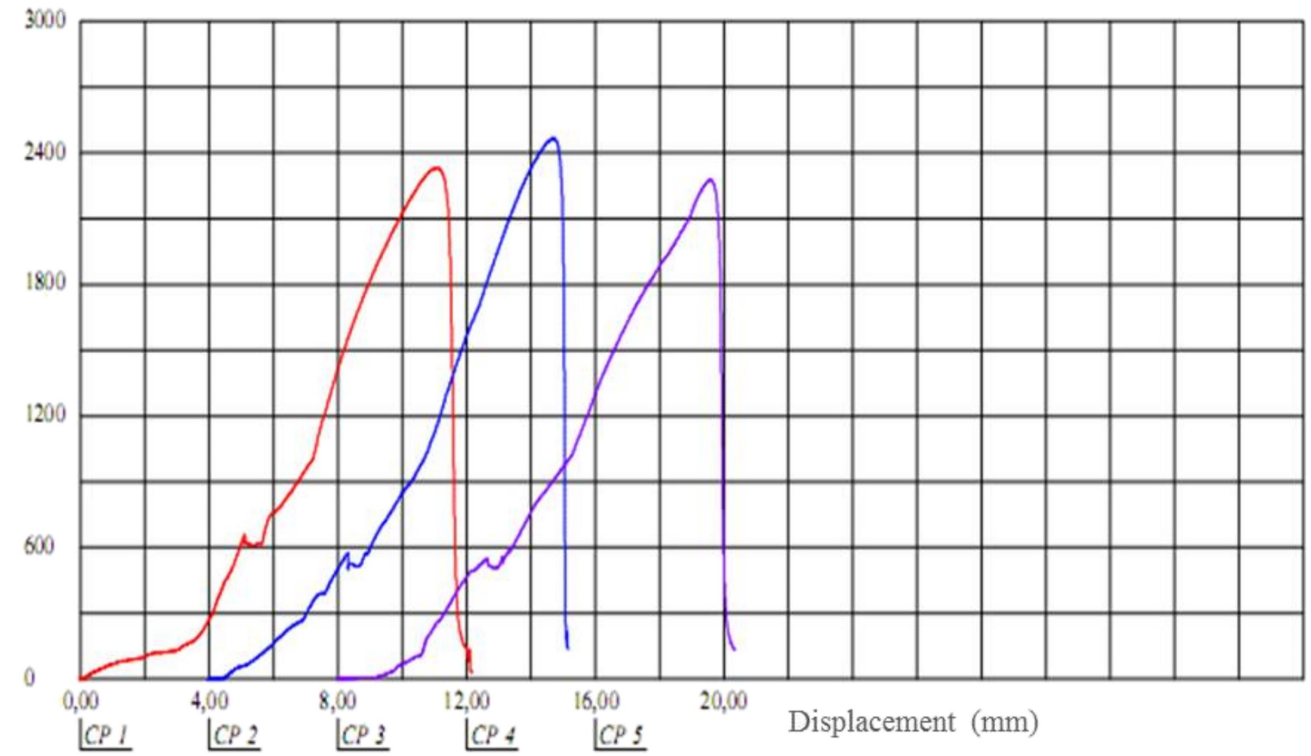

\subsection{Verification of the minimum shear resistance according to Argentine specifications with SBT (UNE- EN} 12697-48 standard)

Since the Argentine technical specification establishes a minimum Smax of 0.7 MPa according to SBT (DNV 2017), which is different from the test applied in this study, the question arises whether the results obtained in the implemented test are comparable to the specified one.

Considering that LEMaC laboratory does not have the SBT device but does have the LCB test, and that there is a correlation between them, the latter was used to do the aforementioned verification. The LCB test is one of the two tests admitted by the Spanish specifications, which according to NLT-382 standard, allows the use of both devices, named A (SBT with Leutner device) and B (LCB Test). These two procedures were collected in NCHRP Report 712 by Mohammad (2012[AQ3]) and are well-known by experts in the field. For the correlation, it was considered what was observed by Berenguer et al. (2017) with respect to the Spanish specification: device B showed 20\% lower shear stresses than Device A.

Therefore, complementary tests were carried out by means of LCB Testing equipment, on double specimens of $100 \mathrm{~mm}$ in diameter, at a speed of $2.5 \mathrm{~mm} / \mathrm{min}$ and at temperature of $20^{\circ} \mathrm{C}$ as required by the standard, with the results being increased by $20 \%$ to compare them to the ones obtained from the SBT Test. Double specimens were moulded by means of the procedure described in the previous section, with the optimum tack coat content obtained also in the previous stage.

\subsection{Determination of the optimum tack coat content for milled surfaces}

Milling equipment produces various surface texture results (Figure 7) such as standard milling (left), fine milling (centre) and micro-milling (right) (Bonfim 2008).

Figure 7. Types of milling (Bonfim 2008).
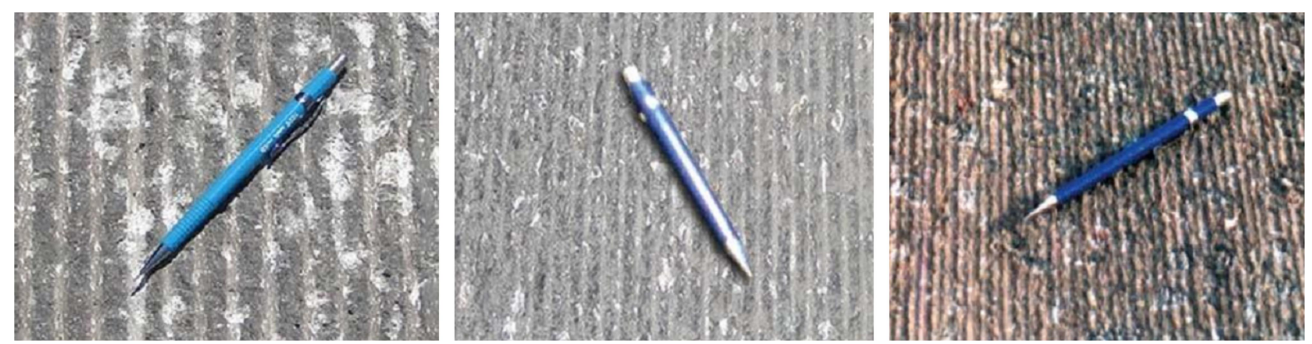

Taking into account some values obtained from the literature review, six milling patterns with the characteristics shown in Table 1 were considered for this study (The Asphalt Contractor 2011, Wirtgen 2013, Bussard 2014, Montetrusque et al. 2015).

Table 1. Cases of milling patterns to be analysed.

\begin{tabular}{|l|c|c|}
\hline Case & Distance between rows $(\mathrm{mm})$ & Milling depth $(\mathrm{mm})$ \\
\hline 1 & 8.0 & 1.0 \\
\hline 2 & 11.4 & 2.4 \\
\hline
\end{tabular}




\begin{tabular}{|l|l|l|}
\hline 3 & 14.8 & 3.8 \\
\hline 4 & 18.2 & 5.2 \\
\hline 5 & 21.6 & 6.6 \\
\hline 6 & 25.0 & 8.0 \\
\hline
\end{tabular}

This step analyses whether it is necessary to increase the dosage proportionally to the increase of area generated by the resulting texture after milling. The doubt arises because it is likely that an excessive increase in the amount of tack coat is not distributed evenly over the milled surface, due to the emulsion flow, which can lead to an excessive deposit in the valley of the grooves. To analyse this, a laboratory experience is carried out on a specimen that simulates milling of Case 3. The dosage of tack coat proportionally increased to the increment of the contact area at the interface is applied in the laboratory with a brush. This specimen is then sawn and observed with an Olympus SZ61 magnifying glass, with an approximate magnification of 45x, achieving images like those in Figure 8 . It is confirmed the validity of the hypothesis made, since it is clear that the deposition of bituminous tack coat in the valleys of the milling is bigger than that obtained in the ridges.

Figure 8. Disposition of tack coat achieved in laboratory.
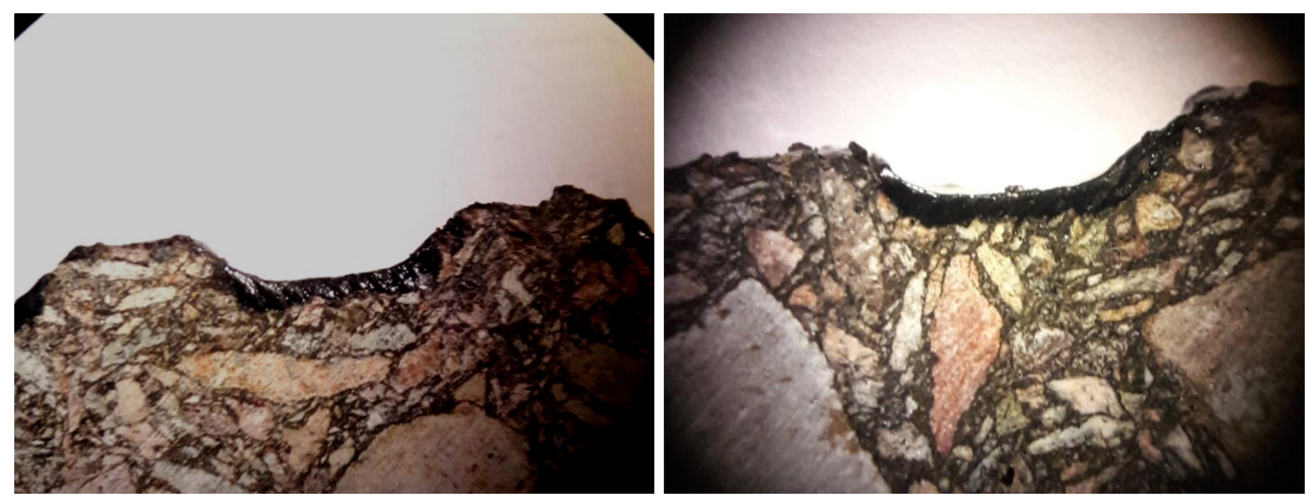

Next, situations that represent an increase of the optimum dosage in 3/3, 2/3, 1/3 and 0/3 of proportion of the contact area increase at the interface are studied to take into account the milling process. Therefore, the optimum dosage was multiplied by a coefficient of increase (Cl) which was calculated from the ratio between the milled area and the smooth area and then varied as $100 \%, 66 \%, 33 \%$ and $0 \%$.

These four situations were considered for the six cases of milling simulation described in Table 1. Double specimens to be analysed were manufactured, establishing a number of three replicates per case. After casting the base layers, the surface sawing of the specimens is proceeded, as shown in Figure 9 (for a specimen corresponding to Case 5). Figure 10 shows the specimens prepared for Situation 4, as an example. Again, Marshall density is determined and given that the results verify the moulding procedure adopted the test can be performed. It should be noted that because the main bending of the pavement is in its longitudinal direction and that the milling presents its toothed surface in this direction, the tests are performed with the double specimen arranged according to the orientation that can be observed in Figure 11.

Figure 9. Sawing of a sample from Case 5.

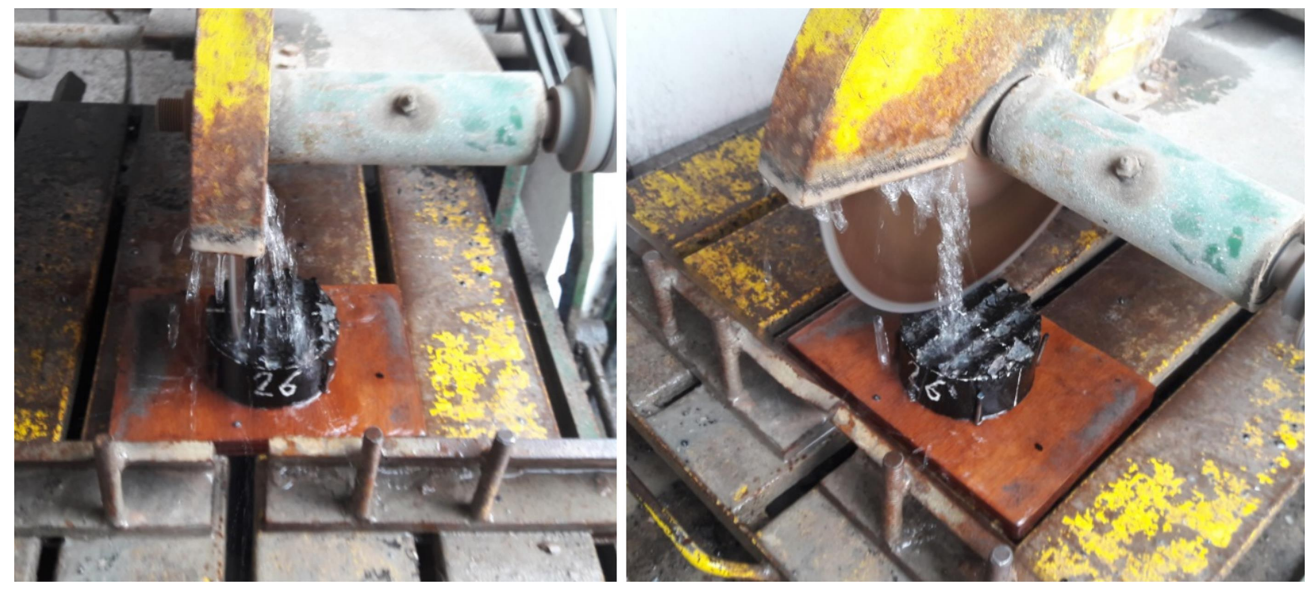

Figure 10. Samples of Situation 4. 


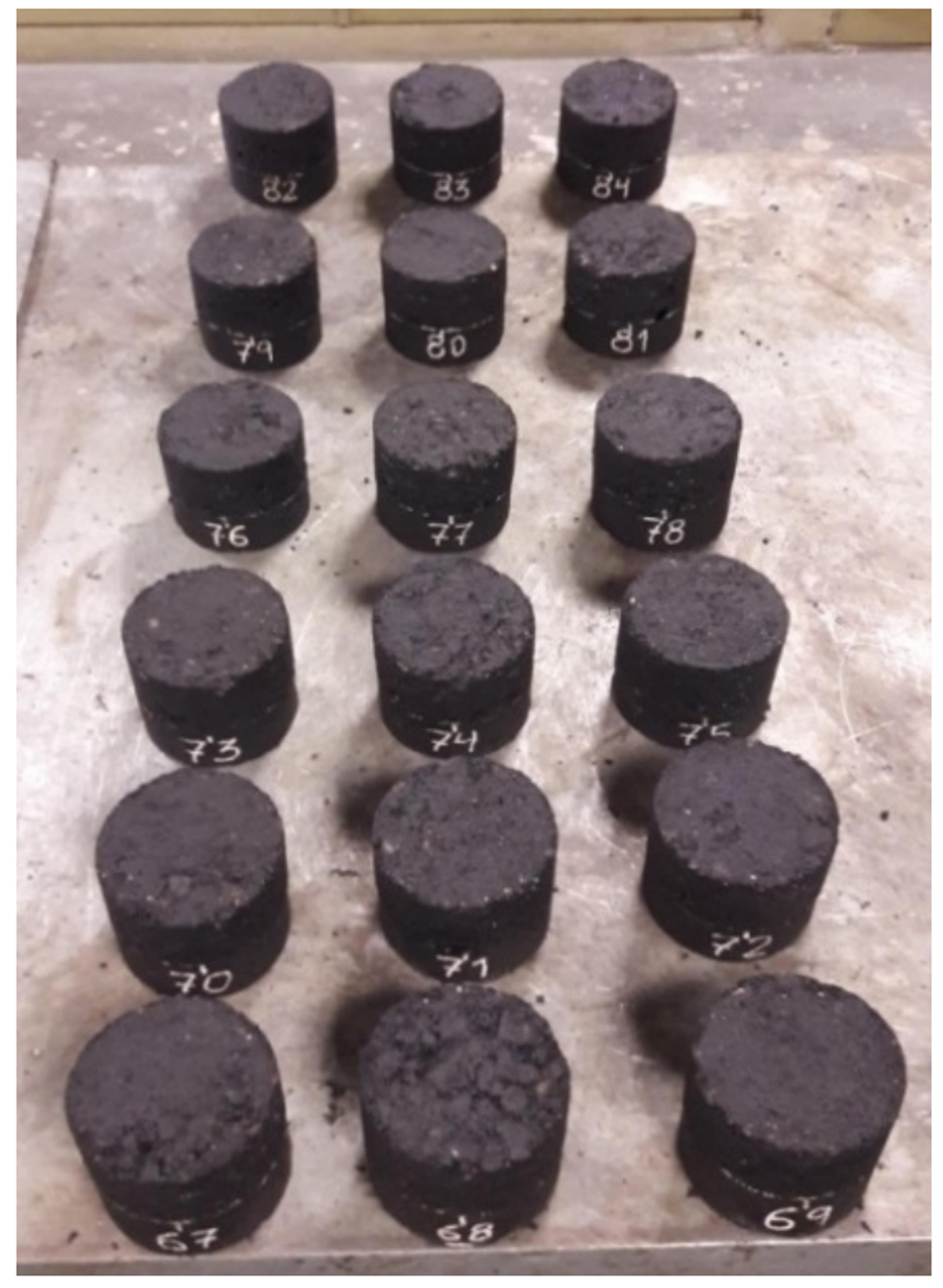

Figure 11. Sketch of stresses applied. 


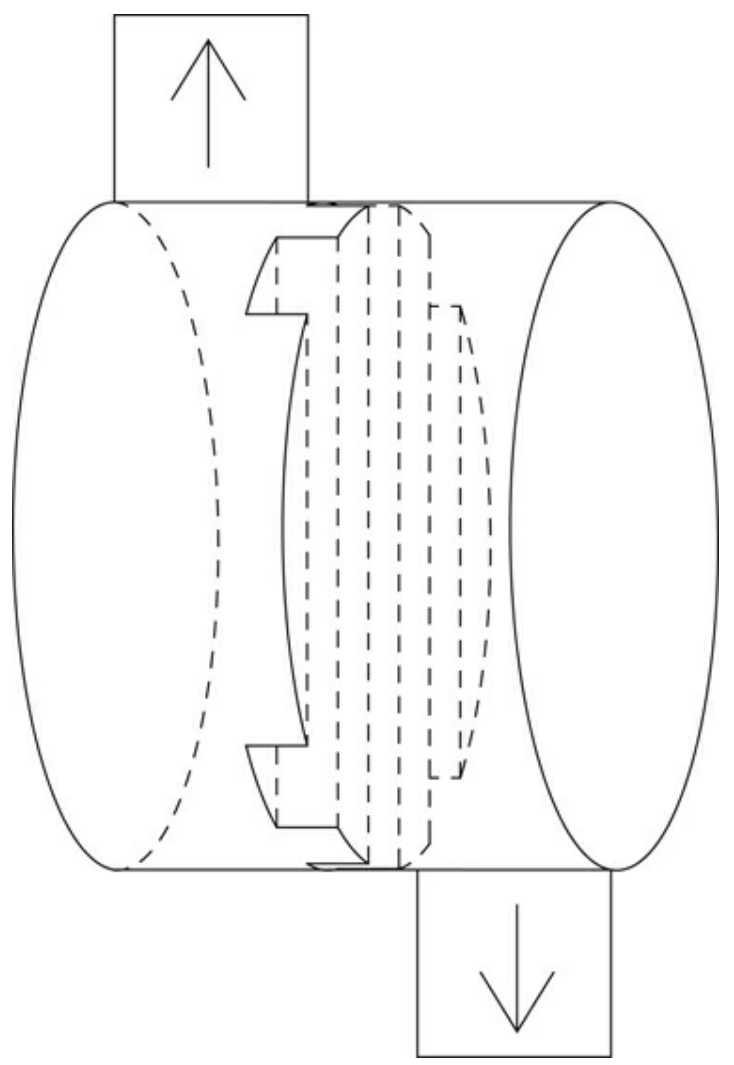

\subsection{Correlation between dosage increase in milled surfaces and texture}

By having the results of the increments of area $\Delta$ (Area) registered with different combinations of width and depth of the grooves, regression models can be found (by numerical simulation for example) that allow estimating $\Delta($ Area) in future applications, from the diameters obtained using an analogous test methodology to that of the Sand Patch Test (IRAM 1997 Argentine Standard). Following this work line, the authors defined a formula that allows estimating the Coefficient of the Area Increase (CAl), that is, the ratio between the surface area of the milled interface with respect to the surface area of a smooth interface, as a function of the Diameter of the Sand Patch $(D S P)$ resulting for a sand volume of $40 \mathrm{~cm}^{3}: C A l=5.03 D S P^{-0.41}$ (Rivera et al. 2017).

The correlation was validated in laboratory on samples representing the six established cases, simulating the different degrees of milling through the use of a diamond blade (Figure 12). Then the DSP were measured in orthogonal directions and the averages were taken as reference for the cases studied (Table 2).

Figure 12. Milling Simulation Case 1.

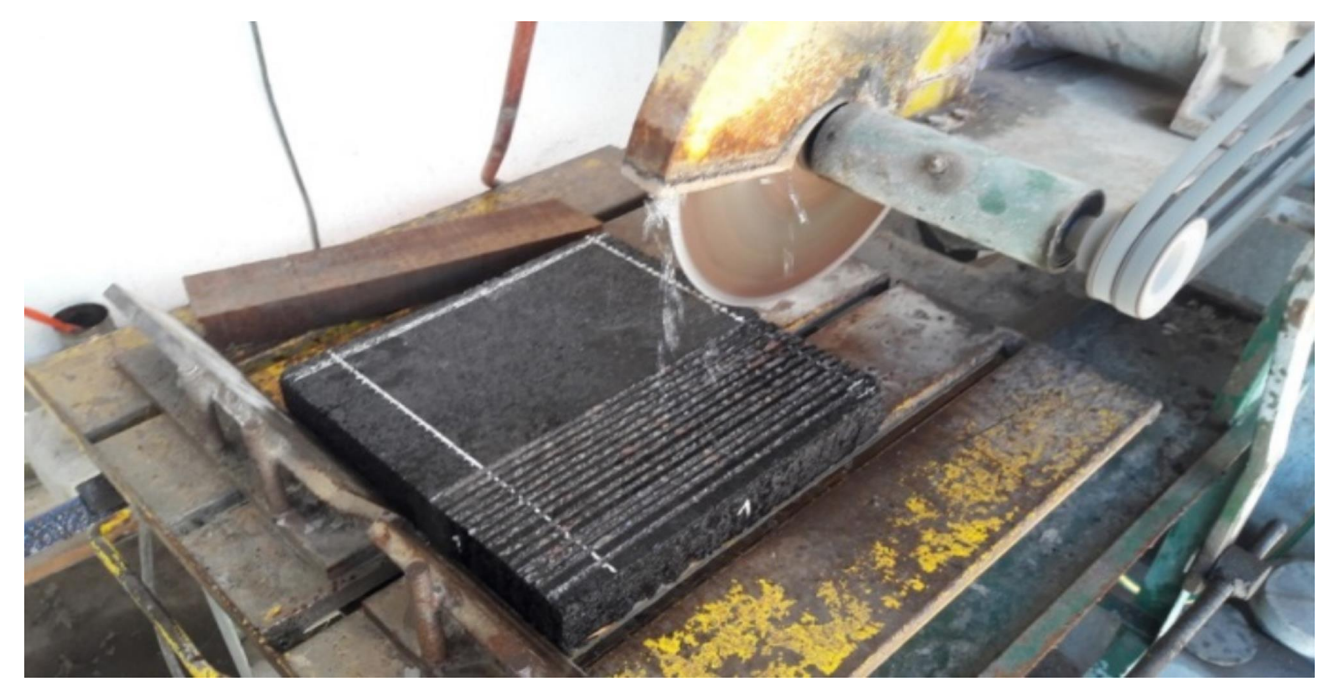

Table 2. Diameters of the sand patch.

\begin{tabular}{|l|l|l|l|}
\hline Case & $D_{1}(\mathrm{~cm})$ & $D_{2}(\mathrm{~cm})$ & DSP $(\mathrm{cm})$ \\
\hline 1 & 23.8 & 24.5 & 24.2 \\
\hline 2 & 20.0 & 19.6 & 19.8 \\
\hline
\end{tabular}




\begin{tabular}{|l|l|l|l|}
\hline 3 & 16.0 & 16.1 & 16.1 \\
\hline 4 & 12.8 & 13.1 & 13.0 \\
\hline 5 & 11.5 & 11.7 & 11.6 \\
\hline 6 & 10.2 & 10.1 & 10.2 \\
\hline
\end{tabular}

Figure 13 shows a cross-section that comes from a sample extracted on site after the milling process (in the upper image) and an image of the section achieved for Case 3 (in the lower picture), which can be assumed characteristic of the actual situation (both images on the same scale). The comparative visual analysis demonstrates the similarity achieved with the milling simulation technique.

Figure 13. Real milling profile (upper image) versus sawing simulation (bottom image).
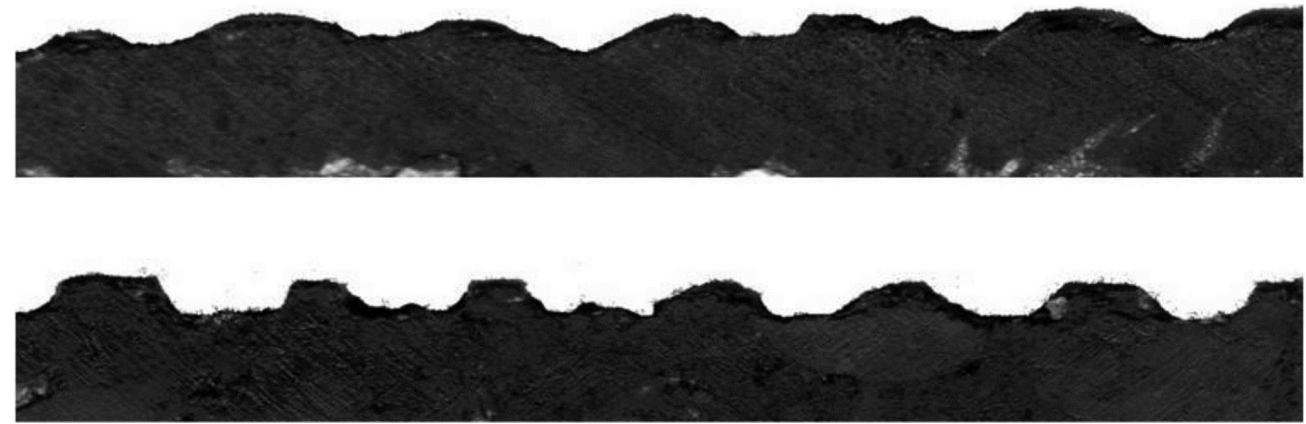

In addition, Table 3 shows the average and standard deviation values obtained from field observations, which are representative for the 6 cases to be analysed, according to the dimensions shown in Figure 14.

Figure 14. Dimensions of the serrated profile.

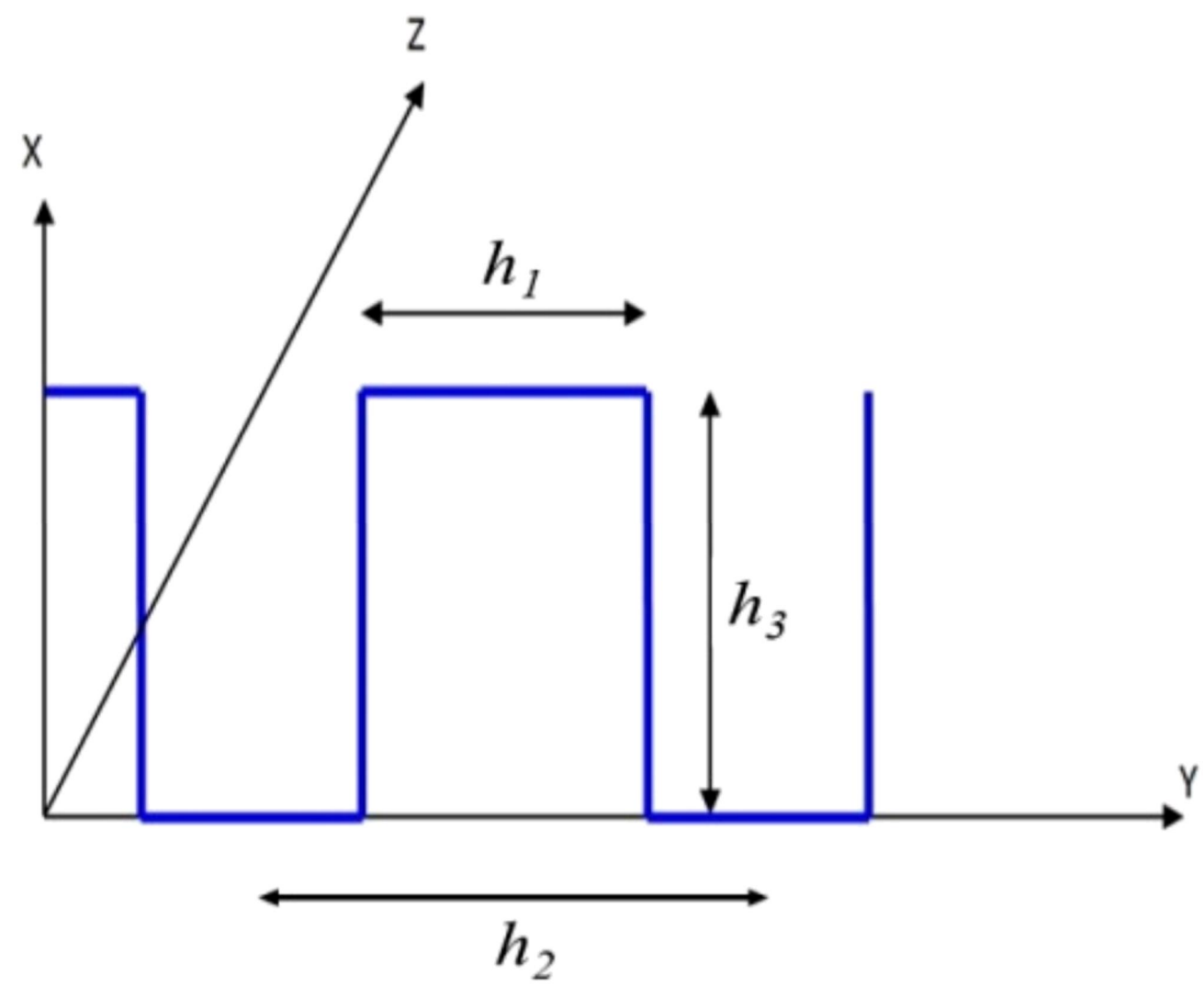

Table 3. Dimensions of the serrated profiles.

\begin{tabular}{|l|l|l|l|l|l|}
\hline & \multicolumn{2}{|c|}{$h_{1}$} & \multicolumn{1}{c|}{$h_{2}$} & \multicolumn{2}{c|}{$h_{3}$} \\
\hline Case & $\mu(\mathrm{mm})$ & $\sigma(\mathrm{mm})$ & $\mu(\mathrm{mm})$ & $\mu(\mathrm{mm})$ & $\sigma(\mathrm{mm})$ \\
\hline 1 & 2.9 & 0.8 & 8.0 & 1.0 & 0.4 \\
\hline
\end{tabular}




\begin{tabular}{|l|l|l|l|l|l|}
\hline 2 & 4.1 & 1.1 & 11.4 & 2.4 & 0.9 \\
\hline 3 & 5.3 & 1.4 & 14.8 & 3.8 & 1.4 \\
\hline 4 & 6.5 & 1.7 & 18.2 & 5.2 & 1.9 \\
\hline 5 & 7.8 & 2.0 & 21.6 & 6.6 & 2.4 \\
\hline 6 & 9.0 & 2.4 & 25.0 & 8.0 & 3.0 \\
\hline
\end{tabular}

\subsection{Application of the methodology to a real case}

Studies were carried out on a road work where an asphalt layer was milled and there is a remaining thickness of asphalt mixture to be overlaid. The work examined is the Provincial Road No. 215, in a section that will be subjected to carriageway widening and pavement rehabilitation between the towns of Coronel Brandsen and San Miguel del Monte, Province of Buenos Aires, Argentina. Among the items of this work are the milling of the asphalt layer in $5 \mathrm{~cm}$ depth, the application of a tack coat and the placement of an overlay type CAC-D19. On site, a remaining asphalt layer of approximately $8 \mathrm{~cm}$ thick is observed, over a Portland cement concrete pavement. So, texture determinations were made in order to measure DSP values with the methodology analogous to the developed Sand Patch Test (Figure 15).

Figu re 15. Determinations of DSPS on site.

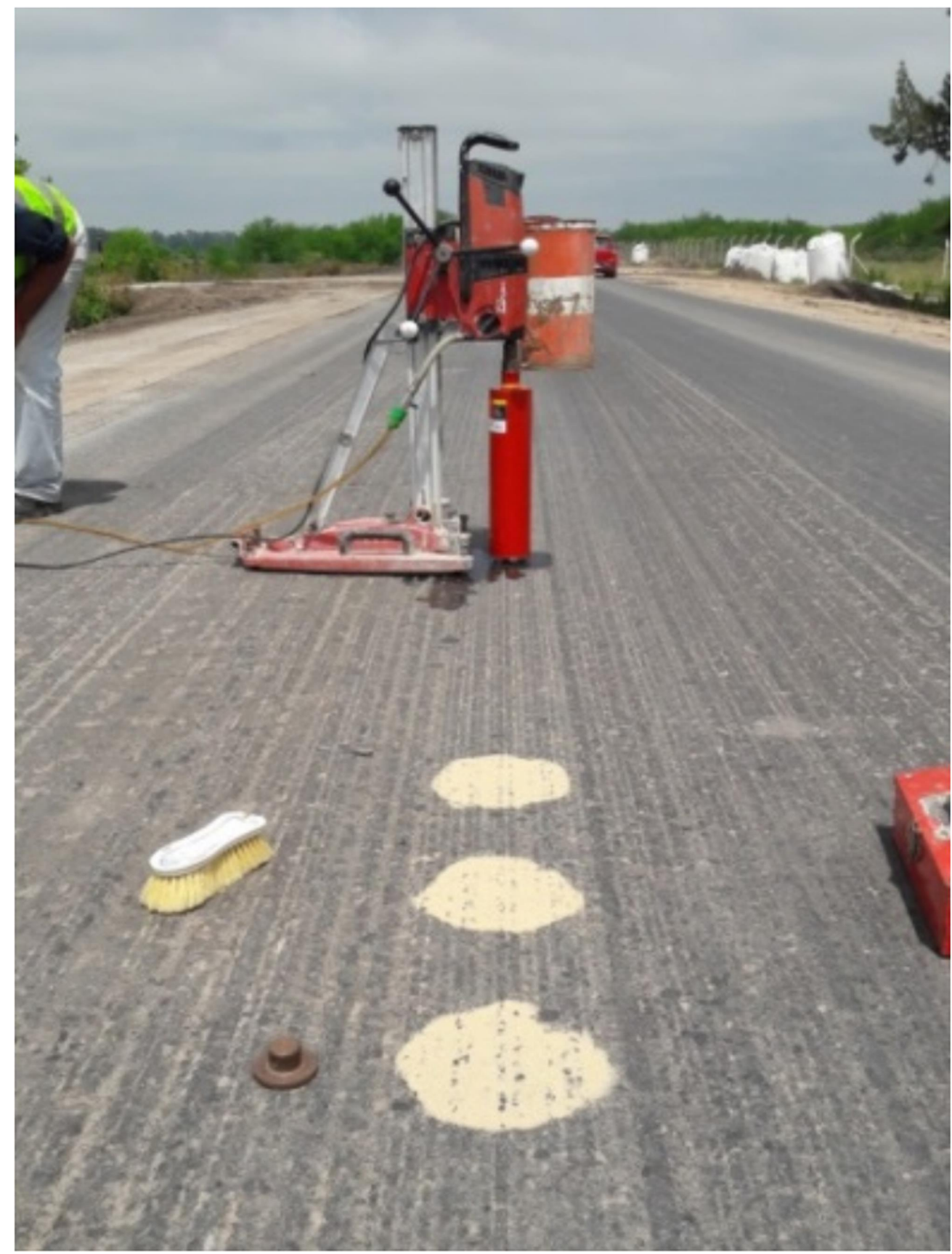

Next, 9 cores were extracted with a diameter of $10 \mathrm{~cm}$, from the remaining asphalt mixture in a single line, in the sector where the 
aforementioned determinations were made; Figure 16. The cores were cut into $5 \mathrm{~cm}$ height, and the remaining material was kept and used for asphalt bitumen content extraction and aggregates recovery. Since the results obtained were similar to those of the asphalt mixture used in the laboratory; the tack coat was applied in the same dosage for the comparative analysis (named Dosage I). Considering the parameters defined in the previous section, three dosages were applied in total, corresponding to the following situations:

Figure 16. Extraction of cores.

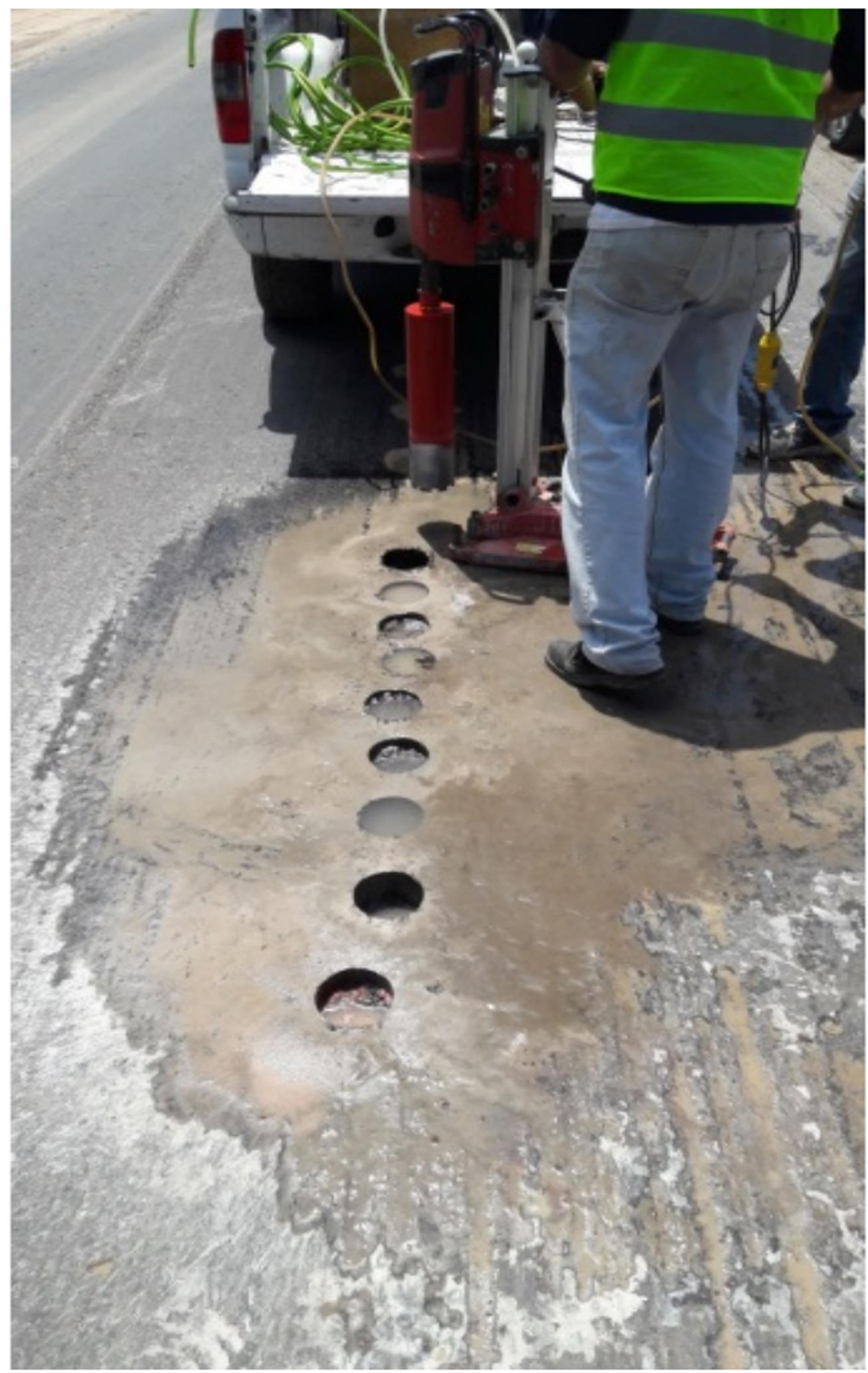

- Dosage I: tack coat dosage established for the interface on smooth surfaces.

- Dosage II: tack coat dosage using the formula developed to estimate the TCIC.

- Dosage III: tack coat dosage calculated from direct increase of the contact surface area at the interface, using the CAl parameter.

An asphalt mixture was prepared in laboratory and used to simulate the overlay in fabrication of the double specimens, which were tested with the developed equipment. 


\section{Results and discussion}

\subsection{Optimum tack coat content for non-milled surface and specification verification}

A summary in Table 4 collects the results of maximum shear stress Smax and displacement TD at breaking point for the tack coats dosages studied.

Table 4. Average values of Smax and TD obtained for the different tack coat dosage.

\begin{tabular}{|l|c|c|c|c|}
\hline & \multicolumn{2}{|c|}{ Smax } & \multicolumn{2}{c|}{ TD } \\
\hline Dosage $\left(1 / \mathrm{m}^{2}\right)$ & Mean (MPa) & COV (\%) & Mean (MPa) & COV (\%) \\
\hline 0.0 & 0.268 & 7.37 & 13.0 & 14.47 \\
\hline 0.1 & 0.300 & 4.12 & 11.1 & 3.84 \\
\hline 0.2 & 0.318 & 12.68 & 9.9 & 2.62 \\
\hline 0.3 & 0.327 & 5.19 & 10.1 & 10.56 \\
\hline 0.4 & 0.303 & 5.85 & 11.3 & 2.82 \\
\hline
\end{tabular}

A highest Smax value attainable in a dosage between $0.25 \mathrm{I} / \mathrm{m}^{2}$ and $0.3 \mathrm{I} / \mathrm{m}^{2}$ can be deduced. The observed fact is verified by elaborating the samples with $0.25 \mathrm{I} / \mathrm{m}^{2}$ of bituminous tack coat. An average Smax $=0.325 \mathrm{MPa}$ is obtained, which is very close to that obtained for 0.3 $\mathrm{I} / \mathrm{m}^{2}$ dosage. An optimum dosage of $0.25 \mathrm{I} / \mathrm{m}^{2}$ is selected because this means a similar response with less tack coat.

Three specimens (A, B and C) manufactured with this dosage, $0.25 \mathrm{I} / \mathrm{m}^{2}$, were tested with LCB shear device and the results obtained are shown in Table 5. Figure 17 shows an image of the device during the performance of the tests. In all cases, the breaking occurred at the interface. According to the results obtained from Smax (0.898 MPa in average), it can be deduced that these bilayer specimens meet the values specified by the Highway Administration, ratifying the analysed dosage of $0.25 \mathrm{I} / \mathrm{m}^{2}$.

Figure 17. LCB Test. 


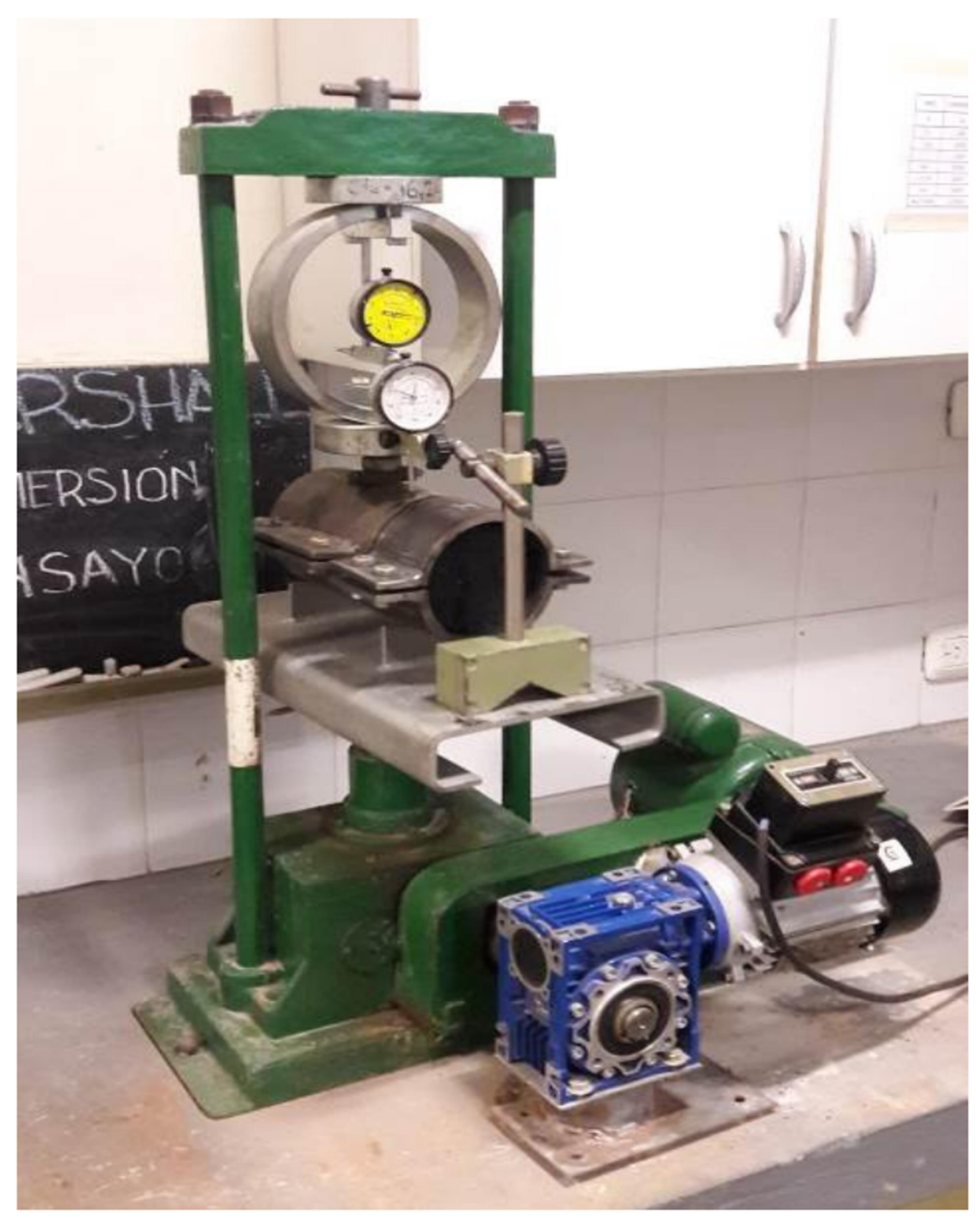

Table 5. Results of LCB test.

\begin{tabular}{|l|c|c|c|c|}
\hline Sample & Load $(\mathrm{kg})$ & Smax in LCB (MPa) & Smax corrected SBT (MPa) & TD (mm) \\
\hline A & 1250 & 0.772 & 0.926 & 1.6 \\
\hline B & 1218 & 0.752 & 0.902 & 1.9 \\
\hline C & 1169 & 0.721 & 0.866 & 1.7 \\
\hline Mean & 1212 & 0.748 & 0.898 & 1.7 \\
\hline COV (\%) & 3.4 & 3.4 & 3.4 & 8.8 \\
\hline
\end{tabular}

4.2. Analysis of shear strength for the cases studied with milled surfaces and correlation between dosage increase in milled surfaces and texture

Six different milling patterns (Table 1 ) of texture were prepared on the bottom specimens, which were adhered to the top layer with four different dosages:

- Situation 1: optimum tack coat content increased proportionally to the surface area increase (being the coefficient of increase, $\mathrm{CI}$, the ratio between the milled area and the smooth area)

- Situation 2: optimum tack coat content increased by $66 \%$ of the area increase

- Situation 3: optimum tack coat content increased by $33 \%$ of the area increase 
All double specimens were tested with the developed equipment used for the smooth surface optimum tack coat content determination. In Situations 1 and 4, the specimen breaking occurred mostly in the area covered by the tack coat, while in Situations 2 and 3 the specimen breaking took place partly in the tack coat and partly in the texture of the specimen in the interface. The results obtained allow the development of Table 6 and Table 7, where the average values of Smax and TD, respectively, are reported for the corresponding values of coefficient of increase of the tack coat $(\mathrm{Cls})$, in each case and each situation.

Table 6. Summary of Smax results for tests on milled surface.

\begin{tabular}{|c|c|c|c|c|c|c|c|c|c|}
\hline & \multicolumn{3}{|c|}{ Case 1} & \multicolumn{3}{|c|}{ Case 2} & \multicolumn{3}{|c|}{ Case 3} \\
\hline & $\mathrm{Cl}$ & Smax (MPa) & $\operatorname{cov}(\%)$ & $\mathrm{Cl}$ & $\operatorname{Smax}(\mathrm{MPa})$ & $\operatorname{cov}(\%)$ & $\mathrm{Cl}$ & $\operatorname{Smax}(\mathrm{MPa})$ & $\operatorname{COV}(\%)$ \\
\hline Sit. 1 & 1.363 & 0.187 & 17.4 & 1.479 & 0.227 & 21.4 & 1.612 & 0.235 & 2.2 \\
\hline Sit. 2 & 1.242 & 0.263 & 19.3 & 1.319 & 0.286 & 27.0 & 1.408 & 0.256 & 4.7 \\
\hline Sit. 3 & 1.121 & 0.334 & 8.9 & 1.160 & 0.313 & 5.4 & 1.204 & 0.355 & 11.4 \\
\hline \multirow[t]{3}{*}{ Sit. 4} & 1.000 & 0.151 & 21.8 & 1.000 & 0.215 & 3.0 & 1.000 & 0.256 & 17.2 \\
\hline & \multicolumn{3}{|c|}{ Case 4} & \multicolumn{3}{|c|}{ Case 5} & \multicolumn{3}{|c|}{ Case 6} \\
\hline & $\mathrm{Cl}$ & Smax (MPa) & COV (\%) & $\mathrm{Cl}$ & Smax (MPa) & COV (\%) & $\mathrm{Cl}$ & Smax (MPa) & COV (\%) \\
\hline Sit. 1 & 1.760 & 0.214 & 12.0 & 1.841 & 0.257 & 18.8 & 1.945 & 0.202 & 31.9 \\
\hline Sit. 2 & 1.507 & 0.263 & 7.3 & 1.561 & 0.270 & 12.2 & 1.630 & 0.325 & 8.8 \\
\hline Sit. 3 & 1.253 & 0.308 & 5.8 & 1.280 & 0.329 & 9.2 & 1.315 & 0.348 & 4.2 \\
\hline Sit. 4 & 1.000 & 0.247 & 9.4 & 1.000 & 0.269 & 30.9 & 1.000 & 0.300 & 15.5 \\
\hline
\end{tabular}

Table 7. Summary of TD results for tests on milled surface.

\begin{tabular}{|c|c|c|c|c|c|c|c|c|c|c|c|c|}
\hline & \multicolumn{2}{|c|}{ Case 1} & \multicolumn{2}{|c|}{ Case 2} & \multicolumn{2}{|c|}{ Case 3} & \multicolumn{2}{|c|}{ Case 4} & \multicolumn{2}{|c|}{ Case 5} & \multicolumn{2}{|c|}{ Case 6} \\
\hline & $\mathrm{Cl}$ & $T D(\mathrm{~mm})$ & $\mathrm{Cl}$ & $T D(\mathrm{~mm})$ & $\mathrm{Cl}$ & $T D(\mathrm{~mm})$ & $\mathrm{Cl}$ & $T D(\mathrm{~mm})$ & $\mathrm{Cl}$ & $T D(\mathrm{~mm})$ & $\mathrm{Cl}$ & $T D(\mathrm{~mm})$ \\
\hline Sit. 1 & 1.363 & 7.6 & 1.479 & 4.5 & 1.612 & 5.9 & 1.760 & 5.2 & 1.841 & 6.2 & 1.945 & 6.2 \\
\hline Sit. 2 & 1.242 & 8.8 & 1.319 & 7.2 & 1.408 & 4.9 & 1.507 & 4.1 & 1.561 & 7.3 & 1.630 & 7.0 \\
\hline Sit. 3 & 1.121 & 7.5 & 1.160 & 4.7 & 1.204 & 7.7 & 1.253 & 7.4 & 1.280 & 8.6 & 1.315 & 7.8 \\
\hline Sit. 4 & 1.000 & 3.0 & 1.000 & 4.7 & 1.000 & 5.9 & 1.000 & 8.2 & 1.000 & 7.2 & 1.000 & 7.3 \\
\hline
\end{tabular}

Situation 3 shows the highest results of shear stress. So the corresponding values of $\mathrm{Cl}$ were defined as the Tack Coat Increment Coefficients (TCIC) and were used in the model resulting from the whole experience to establish the Increased Tack Coat Dosage (ITCD) from the Tack Coat Dosage determined for the smooth interface $(T C D)$, by means of the formula ITCD = TCIC. TCD.

To determine the ITCDs as a function of the DSPs, it is then necessary to correlate the values obtained for each case, collected in Table 2, with the established optimum Cls (assumed now as the ITCDs). Table 8 shows the values of both variables to be correlated and Figure 18 presents the graph with the correlation obtained.

Figure 18. TCIC versus DSP. 


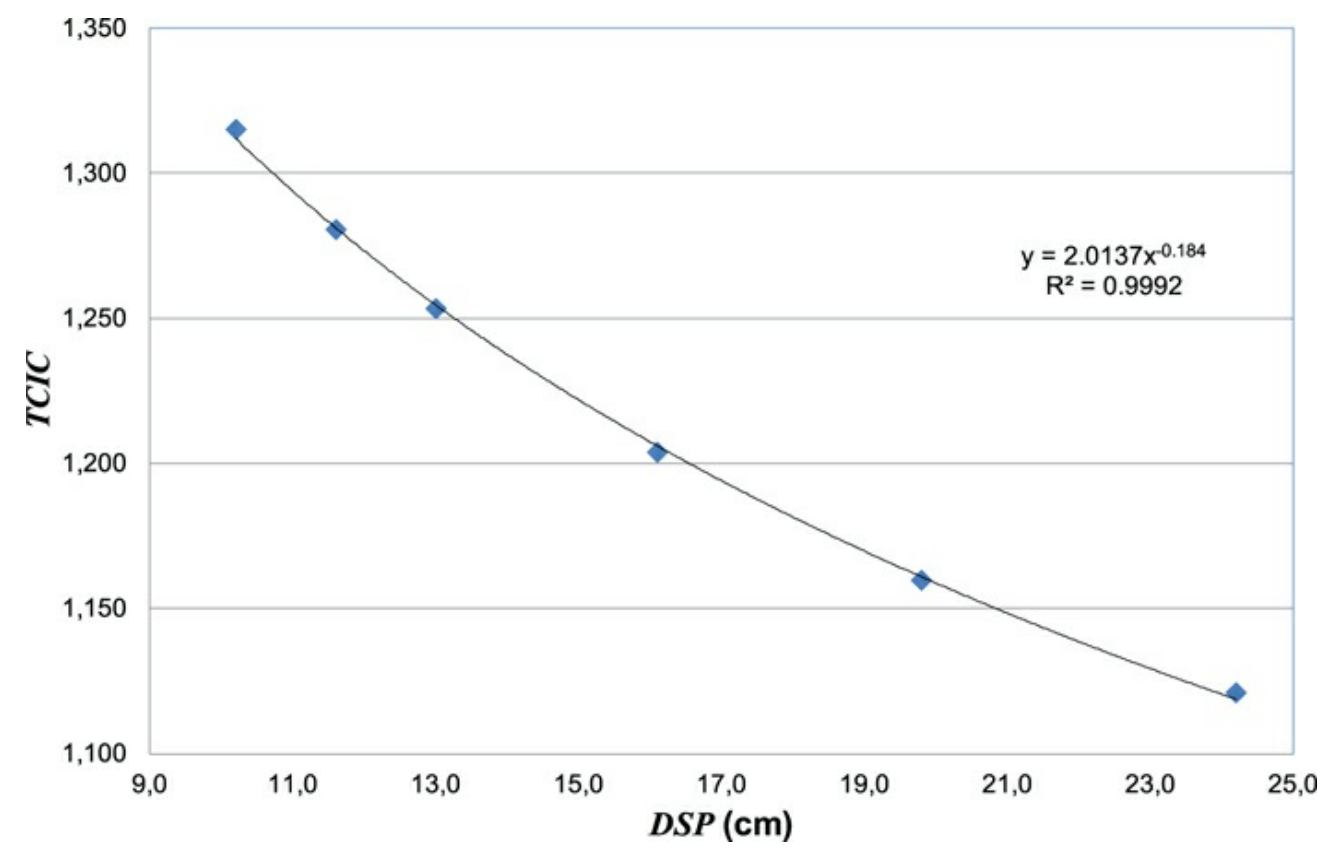

Table 8. TCIC values versus DPA

\begin{tabular}{|l|l|l|}
\hline Case & $T C I C$ & $D S P(\mathrm{~cm})$ \\
\hline 1 & 1.121 & 24.2 \\
\hline 2 & 1.160 & 19.8 \\
\hline 3 & 1.204 & 16.1 \\
\hline 4 & 1.253 & 13.0 \\
\hline 5 & 1.280 & 11.6 \\
\hline 6 & 1.315 & 10.2 \\
\hline
\end{tabular}

As shown in Figure 18, a potential function can be fitted by regression to the point cloud, which allows obtaining a coefficient of determination $R^{2}=0.99$, which complies with the empirical threshold generally established for studies of this type $\left(R^{2}=0.90\right)($ Bello 2016$)$. The formula that finally allows to establish the $T C I C$ according to the $D S P$, resulting for a sand volume of $40 \mathrm{~cm}^{3}$, is then $T C / C=$ $2014 \times D S P^{-0.184}$.

\subsection{Analysis about the methodology proposed}

In a road work, several homogeneous sections to be milled and rehabilitated may be identified, either because this task is carried out with different equipment or with the same equipment but with some adapted parts (for example, for maintenance reasons: change of milling grinds, modification of the milling drum, etc.) or by the same variability in the use of such equipment and its operator, etc. The methodology proposed here can be used starting from some direct measurement for determining the optimum dosage to be used in the case of a smooth interface. Then it is necessary to adjust the dosage according to the measurements made using the methodology analogous to the Sand Patch and the application of the developed model, for each type of homogeneous section identified in the work. Another way of using the procedure is extracting cores from the wearing course after the milling process and having previously made the corresponding measurements with the methodology analogous to the Sand Patch developed, as a 'test section' in each homogeneous section. With these cores and with the material to be used in the overlay, double specimens are prepared and the optimum content of tack coat is determined for the interface with that specific milling texture. This allows applying the model developed in inverse mode on that established dosage, in such a way as to determine virtually what the optimum dosage of tack coat would be if the test was carried out for the case of smooth interface. Once this dosage is calculated, the adjustment is then made according to the measurements taken using the methodology analogous to the Sand Patch and the application of the model developed in each type of homogeneous section registered in the work, as in the first option.

\subsection{Application of the methodology developed to a real case}

Table 9 shows the measured $D S P$ values on the milled surface of the pavement, which lead to an average final average $D S P$ value of 21.6 $\mathrm{cm}$. 


\begin{tabular}{|l|c|c|c|}
\hline Measurement & $D_{1}(\mathrm{~cm})$ & $D_{2}(\mathrm{~cm})$ & $D S P(\mathrm{~cm})$ \\
\hline 1 & 22.0 & 21.0 & 21.5 \\
\hline 2 & 21.5 & 21.0 & 21.3 \\
\hline 3 & 21.5 & 22.5 & 22.0 \\
\hline
\end{tabular}

Next, with the 9 cores extracted from the pavement double specimens were prepared using three different dosages:

- Dosage I: tack coat dosage established for the interface on smooth surfaces.

- Dosage II: tack coat dosage using the formula developed to estimate the TCIC.

- Dosage III: tack coat dosage calculated from direct increase of the contact surface area at the interface, using the CAI parameter.

The prepared double specimens are shown in Figure 19 (Dosage I on the left, Dosage II in the centre and Dosage III on the right). The specimens tested in the manner indicated above produce the average results summarised in Table 10.

Figure 19. Double specimens made with cores.

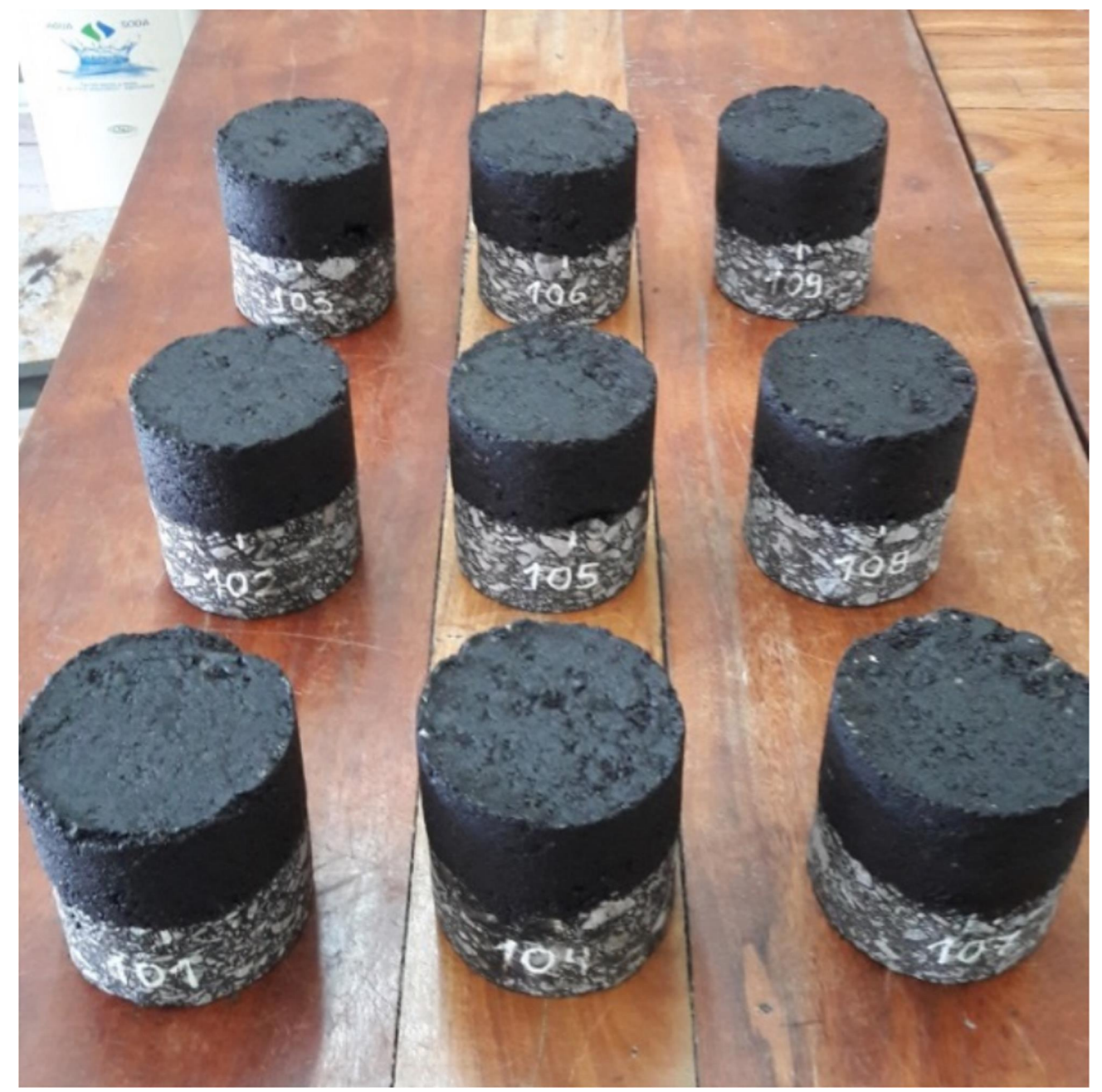

Table 10. Results for Dosages I to III

\begin{tabular}{|c|c|c|c|c|c|}
\hline & & \multicolumn{2}{|c|}{ Smax } & \multirow{2}{*}{$\begin{array}{c}\text { TD } \\
\text { Mean }(\mathrm{mm})\end{array}$} & \multirow[b]{2}{*}{ TCIC } \\
\hline \multicolumn{2}{|c|}{ Dosage $\left(1 / \mathrm{m}^{2}\right)$} & Mean (MPa) & $\operatorname{cov}(\%)$ & & \\
\hline I & 0.25 & 0.164 & 20.2 & 4.7 & 1.000 \\
\hline II & 0.29 & 0.262 & 15.1 & 5.4 & 1.144 \\
\hline III & 0.36 & 0.219 & 16.0 & 4.3 & 1.428 \\
\hline
\end{tabular}


Although the tests carried out do not allow establishing if the optimum dosage is achieved, it is observed that the highest average results of Smax and TD are obtained with Dosage II. Therefore, these results are related to those obtained in the laboratory experiments, noting that the results obtained using a core extracted from an existing pavement, which was milled in the work and a new asphalt 'overlay' manufactured in laboratory, present results lower than those obtained with laboratory base layers (with simulated milling) and new overlay mixtures also prepared in laboratory. This finding is consistent with what was expressed by Berenguer et al. (2017).

\section{Conclusions}

Based on the studies carried out, it can be concluded that:

- The establishment of the dosage of an asphalt tack coat at the interface between asphalt layers of a pavement in rehabilitation, where the previously existing layer is subjected to a surface milling, is a subject that had not been studied deeply, at least as far as regarding the existing materials in Argentina.

- To address this issue, it is useful to start from the knowledge of the texture degree generated by the milling process, given the existing spectrum obtained, for which a test methodology developed analogous to that of the Sand Patch Test can be adopted.

- Through the results of this application it is possible to establish, thanks to the model proposed here, the Tack Coat Increase Coefficient to be used to affect the optimum tack coat content obtained for the case of smooth interface (without milling).

- There are various procedures contemplated in this work, that allow the application of the analysis methodology resulting from the studies carried out in homogeneous sections of milling of road works.

- One of these procedures has been used in a work experience, achieving results that are consistent with those previously obtained in the laboratory, which is a contribution to its validation.

\section{Disclosure statement}

No potential conflict of interest was reported by the authors[AQ4].

\section{References[AQ5]}

The Asphalt Contractor, 2011. How micromilling is saving states money on asphalt road repairs. The Asphalt Contractor Magazine.[AQ13]

Bello, M., 2016. Notes on training on prediction and goodness of fit, Software-Shop Training, Colombia.

Berenguer, J.M., Calvo, C., Molina, J., Gomariz, R., and Peña, J.L., 2017. El ensayo de adherencia de capas de firme según NLT-328/08. Estudio comparativo de los resultados obtenidos con los dispositivos A y B, XIX Ibero-Latin American Asphalt Congress (CILA), Medellín, Colombia.

Bonfim, V., 2008. Fresado de pavimentos asfálticos, Editorial Exceçao, first edition, Brazil.

Brown, S.F., and Brunton, J.M, 1984. The influence of bonding between bituminous layers. Highways Transportation, 31 (5), $16-17$.

Bussard, M., 2014. Milling \& micro milling, P.R. Systems Inc.[AQ6]

D’andrea, A., Tozzo, C., Boschetto, A. and Bottini, L., 2013. Interfase roughness parameters and shear strength, Modern Applied Science (ISSN 1913-1844), Canadian Center of Science and Education, vol 7, n 10, Canada.

Delbono, HL, 2014. Estudio de Grillas Poliméricas en Sistemas Anti-reflejo de Fisuras bajo Solicitaciones Dinámicas. Doctoral Thesis in Materials Engineering, National Technological University, La Plata Regional Faculty, La Plata, Argentina.

Diakhaté, M., et al., 2011. Experimental investigation of tack coat fatigue performance: Towards an improved lifetime assessment of pavement structure interfaces. Construction and Building Materials, 25 (2), 1123-1133.

DNV, 2017. Pliego de especificaciones técnicas generales para concretos asfálticos en caliente y semicaliente del tipo densos, National Highway Administration (DNV), Argentina.

EICAM, 1998. Curso de actualización de diseño estructural de caminos (método AASHTO93). National University of San Juan, Argentina. [AQ7]

Espinoza, M., 2015. Capas de refuerzo con hormigón adheridas como alternativa para la rehabilitación de pavimentos asfálticos, Infraestructura Vial Magazine (ISSN 1409-4045), University of Costa Rica, volume 17, number 30, december, Costa Rica.

Gierhart, D., and Johnson, DR, 2018. Tack coat specifications, materials, and Construction Practices. NCHRP Synthesis of Highway Practice, 516.[AQ8]

Giovanon, O., and Buono, F., 2008. Riego de liga su importancia estructural y análisis tensional, XXXV Asphalt Meeting, Comisión Permanente del Asfalto, Rosario, Argentina.

Giovanon, O., and Pagola, M., 2012. Modelo mecanicista empírico para análisis de pavimentos flexibles desarrollado en Argentina, Carreteras Magazine, Asociación Argentina de Carreteras, number 208, december, pp. 76-86, Argentina. 
IRAM, 1997. IRAM Standard 1850: Agregados. Método de determinación de la profundidad de la macrotextura superficial de un pavimento mediante el círculo de arena, Argentine Institute for Standardization and Certification, Argentina.

Martínez-Echevarría, MJ., 2012. Estudio de compactación en laboratorio para mezclas recicladas en frío con emulsión bituminosa. Doctoral Thesis, University of Granada, Spain.[AQ9]

Miller, J., and Bellinger, W., 2003. Distress identification manual for the long-term pavement performance program, fourth revised edition. Report No. FHWA-RD-03-031, Washington DC, USA.

Mohammad, LN., 2012. Optimization of tack coat for HMA placement. NCHRP Report 712. Transportation Research Board.

Montetrusque, G., Bernucci, L., Leite, F., and Teoro, C., 2015. Avaliação da adherencia de geogrelhas entre camadas asfálticas, Memories of the XVIII Ibero-Latin American Asphalt Congress (CILA), ISBN 978-950-630-031-9, Bariloche, Argentina.

Muench, ST, and Moomaw, T., 2008. De-bonding of hot mix asphalt pavements in Washington state: an initial investigation, TNW 2008-10, Transportation Northwest (TransNow). University of Washington.[AQ10]

NCHRP, 2004. Guide for mechanistic-empirical design of new and rehabilitated pavement structures. National Research Board, 1-37A team. [AQ11]

Raposeiras, A. C., et al., 2013. New procedure to control the tack coat applied between bituminous pavement layers. Construction and Building Materials, 44, 228-235.

Ricci, LA., 2011. Evaluación de adherencia entre capas asfálticas con intercapa de geosintético. Thesis of Master in Transportation Engineering - Road Guidance, University of Buenos Aires, Argentina.

Rivera, JJ, Bianchetto, H., Delbono, H.L., Queizán, A.F., Urruspuru, J., and Morgante, L., 2017. Metodología para estimación de dotación de riego de liga en refuerzos asfálticos sobre superficies fresadas. XIX Ibero-Latin American Asphalt Congress (CILA), Medellín, Colombia.

Romanoschi, S.A., 1999. Characterization of pavement layer interfaces. Louisiana State University and Agricultural \& Mechanical College. [AQ12]

Santagata, F. A., et al., 2009. Statistical investigation of two different interlayer shear test methods. Materials and Structures, 42 (6), 705-714.

Tosticarelli, JR, 2002. Ensayos para evaluar la adherencia entre capas asfálticas: Memories of XXXII asphalt Meeting. Tafí del Valle: Comisión Permanente del Asfalto.

Uzan, J., Livneh, M., and Eshed, Y., 1978. Investigation of adhesion properties between asphalt concrete layers., Proc. Assoc. Asphalt Paving Technologists, St. Paul, Minn, 47, 495-521, USA.

Wirtgen, 2013. Wirtgen cold milling manual, Technology and application. Wirtgen GmbH.[AQ15]

Wirtgen, 2015. El mundo de las fresadoras en frío de Wirtgen. Wirtgen Group Company.[AQ14]

Yaacob, H., Hainin, M.R., Safuan, A., and Chang, F.L., 2014. Information for the Malaysian asphalt industry towards better pavement interlayer bonding, Sains Malaysiana, 43 (3), 467-474, Malaysia.[AQ16] 